\title{
Cultivating Student Adoption of Design Thinking and Entrepreneurial Skills by Addressing Complex Challenges in Healthcare Through Industry Partnerships
}

\section{Dr. Julia A. Scott, Santa Clara University}

Julia Scott is a researcher at the BioInnovation and Design Lab of Santa Clara University. She trained as a neuroscientist at the University of California, Davis. In her current role, she manages projects relating to brain-computer interfaces, as well as machine learning applied to medical imaging and clinical decision support tools.

\section{Evangelia Bouzos, Santa Clara University}

Evangelia Bouzos earned her BS in Bioengineering and MS in Engineering Management and Leadership from Santa Clara University. She is an alumni of the BioInnovation and Design Lab and has participated in the Lab in multiple ways, as student researcher during undergrad and as a program manager during her masters program. Currently, she participates in the Lab as an industry mentor to three student teams and serves as a member of the BioInnovation and Design Lab young alumni advisory board.

\section{Matthew Philip Hendricks, Santa Clara University}

Matthew P. Hendricks has 13 years of experience facilitating institutional fundraising and partnerships across the industry, philanthropic, governmental, and social sectors. At Santa Clara University, he supports an impact-driven, scaffolded model designed to validate, implement, sustain, and scale high-potential initiatives and partnerships. These efforts seek to build upon internal strengths, fill gaps through the identification of partners of choice, and leverage funding from multiple external sources. Matthew earned his BS in Political Science from Santa Clara University.

\section{Dr. Prashanth Asuri, Santa Clara University}

Dr. Prashanth Asuri joined the Bioengineering faculty at Santa Clara University in Fall 2011 after holding research positions in academia and industry. Dr. Asuri earned his Ph.D. in Chemical and Biological Engineering from Rensselaer Polytechnic Institute and M.B.A. with a focus on Leading Innovative Organizations from Santa Clara University. His research efforts focus on the design and development of simple in vitro platforms to understand complex in vivo phenomena. He teaches undergraduate and graduate courses on topics related to tissue engineering, biomaterials, and bioinnovation. Dr. Asuri also serves as the Director of SCU's BioInnovation and Design Lab that partners with industry to empower students to discover, innovate, and address complex challenges within healthcare. 


\title{
Cultivating Student Adoption of Design Thinking and Entrepreneurial Skills by Addressing Complex Challenges in Healthcare through Industry Partnerships
}

\begin{abstract}
This paper highlights the establishment of an on-campus center for biomedical engineering design and innovation (BioInnovation and Design Lab) that partners with industry to apply design thinking and entrepreneurial skills to solve 21 st-century problems across biomedical fields. The students, faculty, and research staff affiliated with the Lab leverage an authentic design process that sources real-world engineering problems and engages multidisciplinary teams of engineers, scientists, and business professionals in an immersive and iterative prototyping process. To scale and sustain the impact of the Lab, a three-way value proposition was developed that aimed to deliver value to the students, faculty, and external partners. The Lab offers students immersive co-curricular experiences and design projects that enable them to work with real industry customers and expert mentors to gain applied skills that advance their careers in healthcare innovation. It aligns and extends the expertise of faculty through key external partnerships by enabling sponsored industry projects and paving the way for long-term partnerships in select technical areas. The Lab creates value for external partners by undertaking research and design projects that address key business objectives. The activities of the Lab are measured against performance indicators directly related to student training and engagement of faculty and industry mentors and adjusted to improve overall efficiency. In addition, we gathered qualitative data to ascertain the successful delivery of the value propositions. Recent lab alumni and industry partners were surveyed to determine whether they received the value that was promised and expected, as well as to discover why the lab was important to them, and what they valued most. We invited feedback from representatives of the university and school corporate and external relations programs, as well as the members of its advisory board to learn more about the overall value the Lab brings to the university and its stakeholders.

1. Introduction

Engineering students interested in pursuing careers in the healthcare industry are in want of experiential learning opportunities that allow them to test the waters and build relevant skills. For the most part, the core engineering curriculum does not prioritize this application, yet at the professional level, there is great demand for engineers in this sector. With the mission of closing this gap for students and the industry, the BioInnovation and Design Lab (hereafter, to be referred as the Lab) was first conceptualized in 2016. The Lab provides curricular and cocurricular opportunities in the arena of healthcare applications, through industry-partnered projects, skills-based bootcamps, student fellowships, entrepreneurial mindset workshops, and seminars. These activities not only bridge the gap between what industry needs from entry level engineers and the skills developed by typical preparation of engineers in universities [1][2], but also helps students embody design thinking and an entrepreneurial mindset [3].
\end{abstract}


Regardless of the discipline applied, a common thread to engineering for healthcare (and other complex problems) is the application of design thinking. A core value of design thinking is the human-centered approach to solutions that can be effectively implemented [4]. In the training process, students are asked to determine the customer's needs and to evaluate whether the proposed design is truly a solution to the problem. Importantly, coming up with an effective design relies on a few habits of mind that are found in many innovators. The KEEN organization comprises these habits as the three C's - curiosity, connections, creating value [5]. In our organization, we describe the entrepreneurial mindset as identifying opportunities to create value or satisfy a human need through ventures requiring new resources or approaches. Further, we place value on empathy for the stakeholders by viewing problems as opportunities, determining tolerance for risk, and prioritizing long-term value creation. For the Lab, this mindset is instilled through the activities listed above, which are both explicit and implicit training.

The Lab's focus on healthcare applications for real-world learning opportunities is part of the larger mission of Santa Clara University to raise a student population who will be the innovators and problem-solvers of their generation. Across our institution, design thinking is a key area of emphasis available to students of all academic majors. Students may take courses (either individually or as a cluster to promote integrative and intentional learning) that teach design thinking methods or apply design thinking in project-based learning. The University has recently established the Ciocca Center for Innovation and Entrepreneurship which, through various functions, supports the development of an entrepreneurial mindset and facilitates student ventures. Within the School of Engineering, all students must complete a senior design project, in which student teams develop a solution to a specific problem statement and present and defend their thesis at the end of the academic year, as a part of the curriculum. Additionally, engineering students have opportunities to contribute to solving humanitarian engineering problems with the Frugal Innovation Hub, tackle energy challenges with the Latimer Energy Lab, or collaborate with USGS and NASA as part of the Robotics Systems Lab. The BioInnovation and Design Lab adds to this network by building bridges with San Francisco Bay Area biotechnology and healthcare companies.

The mission of the Lab is to prepare students to apply design thinking and entrepreneurial skills to solve some of the $21^{\text {st }}$ century's most pressing challenges across biomedical fields. Since 2017, the Lab has engaged students across many disciplines and levels, so that regardless of academic major or experience, there is opportunity to gain practical exposure to healthcare applications. Curated student experiences range from fellowships designed to introduce undergraduates to the biomedical field and entrepreneurial mindset (building the front end of the pipeline) all the way to graduate student research projects that lead to publishable results. The Lab recognizes that diverse entry points are needed for students to begin their careers and accumulate experiences to discern their desired career path. In their way-finding, not every student will stay in healthcare, but participation in the Lab has the lasting impact of teaching them problem solving skills that can be broadly applied to various complex problems.

\section{Core vision for the Lab}

The Lab envisions empowering students with skills and knowledge to address complex challenges that transform global health outcomes and lower healthcare costs. To execute this 
vision, the Lab sources and project manages research and talent development collaborations that offer mutual benefit to the University and its external partners. In addition to pursuing projects for developed markets, the Lab also partners with other centers on campus that place a unique emphasis on humanitarian engineering to create and deploy technology solutions for frontiermarket environments. The students, faculty, and research staff affiliated with the Lab leverage an authentic design process that sources real-world engineering problems and engages multidisciplinary teams of engineers, scientists, and business professionals in an immersive and iterative prototyping process. Such an approach has been conducted by other engineering programs, including those in the NSF-sponsored Pathways to Innovation Program, to successfully cultivate student readiness for careers in innovation and entrepreneurship. James Madison University restructured their engineering program by putting greater agency with the student in defining their curriculum and creating two-year capstone projects, as well as widening student access to entrepreneurship training and engagement in real-world projects [6]. Another example is from University of Pittsburg's Swanson School of Engineering, which overhauled their program, policies, and physical spaces to enable student-directed innovation and entrepreneurship [7]. The co-curricular component was structured under a Product Realization certificate and the extra-curricular component included collaborations with external partners. While the common purpose across these programs is to foster a student mindset that is prepared for real-world problem-solving, the Lab focuses on external partnerships as the central hub of its function (in contrast to curricular programming). Such a project-based approach opens opportunities to students of any discipline within the specialization of healthcare applications.

To scale and sustain its impact, the Lab developed a three-way value proposition that drives value both to internal constituencies (students and faculty) and external constituencies (industry sponsors). For students, it accelerates early-career success through fellowships, expert mentoring, industry-sourced design projects, and supplemental application oriented courses and workshops (e.g. design for FDA regulation). For faculty mentors, it supports real-world research translation, publication, and (as appropriate) commercial integration of their research through connections to industry teams and external funding, as well as the provision of project management. For external sponsors, it facilitates connections with University experts who can take on aligned research and innovation challenges, as well as opportunities to engage and help create a diverse, high-caliber, and well-prepared talent pipeline. Additionally, it provides compelling opportunities for alumni, donors and friends of the University to make contributions of time and money in support of student professional development.

The Lab ensures that its vision and mission are upheld in all the work conducted through the formation of an involved and strong advisory board to guide its activities and initiatives. Acting upon their advice, the Lab developed objectives and key performance indicators to track progress and ensure consistent measures of success across all stakeholder facing activities (Table 1). The primary student-facing objective is to support the development of a pipeline of students who are prepared for careers in healthcare through intensive industry engagement. We introduce students to the breadth of healthcare innovation fields, engage them in workshops, boot camps, and meaningful industry projects to develop their skills and interests. Success against these studentfacing objectives are measured by tracking the numbers of students engaged in industrysponsored projects, co-/extracurricular activities, and mentorship and professional development activities. For faculty, the Lab will seek to support long-term collaborations on industry relevant 
biotech and biomedical device projects, by facilitating industry sponsored projects, funding student and faculty teams, and offering pilot-phase grants. Key results include number of faculty mentors, number of industry sponsored projects, and the number of faculty-conceived projects. Drawing on the expertise of its affiliated faculty, the Lab works with industry sponsors (companies, clinics, and NGOs) to identify and scope collaborative business and technical projects that are exploratory in nature and address a long-term challenge or probe a new market opportunity beyond the capacity or expertise of the sponsor's internal resources. Successful engagement with the external partners is tracked by the number of partners, number of mentors, and the number of return partners. Finally, the Lab will provide opportunities for individual and institutional philanthropists to enhance student success in their career paths, build a pipeline of talent from underrepresented backgrounds, and accelerate R\&D in health technology innovation. Donor engagement will be measured by monitoring the frequency and size of gifts in support of either structured student fellowship programs, or research positions in specific technical focus areas, as well as the number of hours spent volunteering.

Table 1. Objectives and key performance indicators for successful stakeholder engagement.

\begin{tabular}{|c|c|c|}
\hline Stakeholders & Key Objectives & Performance Indicators \\
\hline Students & $\begin{array}{l}\text { - Support career development of } \\
\text { students through projects and co- } \\
\text { /extracurricular activities }\end{array}$ & $\begin{array}{l}\text { - Number of students in projects } \\
\text { - Enrollment in co-/extracurricular activities } \\
\text { - Number of student fellows }\end{array}$ \\
\hline Faculty & $\begin{array}{l}\text { - Source and project manage } \\
\text { industry-relevant projects }\end{array}$ & $\begin{array}{l}\text { - Number of faculty mentors } \\
\text { - Number of industry sponsored projects } \\
\text { - Number of faculty-conceived projects }\end{array}$ \\
\hline $\begin{array}{l}\text { Industry } \\
\text { partners }\end{array}$ & $\begin{array}{l}\text { - Identify industry-sponsored } \\
\text { design projects and research } \\
\text { opportunities }\end{array}$ & $\begin{array}{l}\text { - Number of industry partners } \\
\text { - Number of project mentors } \\
\text { - Number of return partners }\end{array}$ \\
\hline
\end{tabular}

\section{Organizational Structure}

\subsection{Internal Structure}

The organization of the lab is illustrated in Figure 1A. The Lab is led by the director whose primary responsibilities are recruiting industry partners and projects, securing funding from donations, grants and industry partners, and matching projects to faculty and students. The Lab is advised by a board composed of leaders in business and bioengineering and members from University corporate and external relations offices. This board provides accountability and guidance to support the ongoing success and growth of the Lab's mission. The director also works closely with University Relations to identify external partners and funding sources. While the director ties together all the components of the Lab's functions, the faculty mentors are the primary interface with students. Once a project is initiated with a faculty mentor, the faculty person acts as the liaison between the students and the external partner. This person manages the project, provides area expertise, and teaches the students associated professional skills. Primary successes for the faculty mentor are in the student outcomes and building strong relationships 
with the industry mentors. This contrast with a faculty mentoring students in their own lab where the success is mostly linked to scholarly works, future funding, and job security.

A

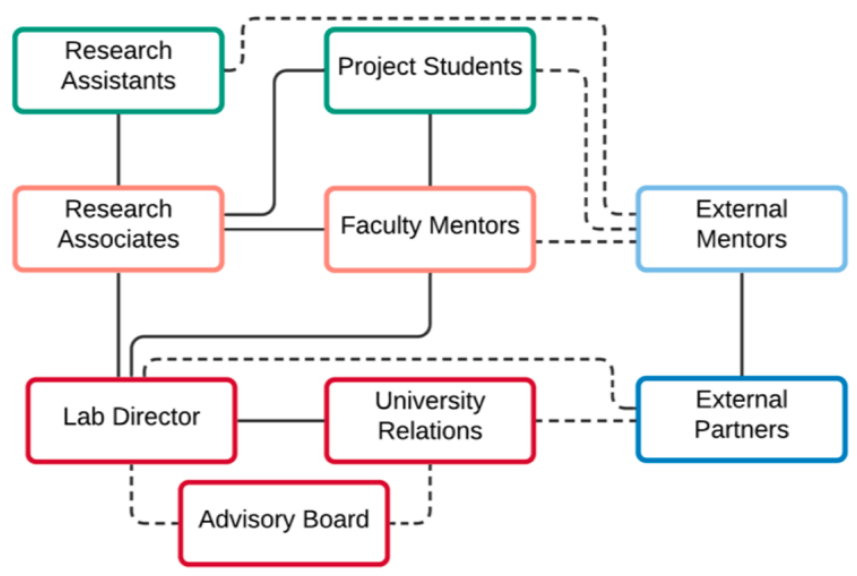

B

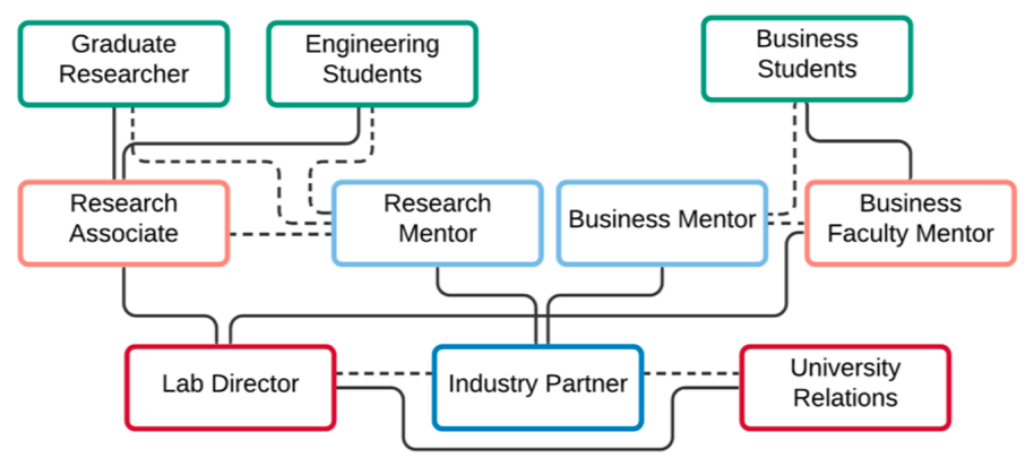

Figure 1. (A) General organizational chart for the Lab and (B) and example of a real industry partner. Students are in green, internal mentors in pink, leadership in red, external partners in dark blue, and external mentors in light blue. Solid lines indicate internal connections, dashed are external.

At the heart of the endeavors of the Lab are the students, who either approach the Lab for wayfinding opportunities or are invited by faculty mentors. A key step in ensuring student success is matching them to a project that aligns with their topical area of interest, current skill level, and sought area of growth. The Lab engages students from first year to master's level in varying capacities. Students may volunteer on a project as a trial, join in the context of a research fellowship, or receive compensation for their efforts in the form of monetary payment, as a research assistant, or academic credit. They may also work on projects that have been adapted to senior design engineering projects. Importantly, the Lab aims to meet the needs of the students and support their educational goals above the work product. Industry mentors, selected by the partner organization, will consult directly with the student team and faculty mentor(s) on a regular basis, typically once or twice a month. In these meetings, students give progress reports, ask questions, and receive feedback. Once or twice an academic year, student teams formally present their work product in the form of reports, presentations, and/or demonstrations and prototypes. Project commitments are typically scheduled over an academic year for completion. 


\subsection{Scope of Work}

The activities of the Lab are not methods or discipline specific. Rather projects are united by the theme of healthcare innovation. For example, teams have designed a training simulator for lab techniques using virtual reality (VR) and built clinical decision support tools via machine learning models, resulting in students from diverse backgrounds and interest areas working with the Lab. Students are represented from departments such as computer science, studio art, and bioengineering. On the university campus, the Lab is not constrained to one site of work. The Lab leverages the distributed resources of the campus for the broad scope of projects. Computational work is supported by the computing infrastructure of the School of Engineering, heavily image-based machine learning uses a dedicated GPU workstation, prototyping projects make use of the Maker lab facilities, VR application development occurs in the VR design studio, and wet lab experiments are conducted in equipped faculty labs. Furthermore, numerous projects do not require specialized resources. This fluidity and campus-wide engagement maximizes student outreach and fosters collaboration between departments and schools.

\subsection{Industry Sponsor Exemplar}

One of our long-standing industry sponsors has been Varian Medical Systems (Industry Partner, Figure 1B), that produces radiotherapy solutions for cancer treatment. Varian engaged with the Lab at two levels - business and applied research (Figure 1B). For the business arm, Varian has been interested in the inclusion of software as a service (SaaS) and cloud computing services as a part of their product portfolio. Utilizing the cloud services would allow Varian to develop continuously evolving treatment solutions that leverage data from hospitals around the world. Given the unique challenges with selling cloud-based service products in the healthcare industry, students were tasked with identifying the standards expected by the consumers (e.g. security and privacy standards) and how to best minimize adoption barriers. Through these efforts, students gained training and practical experience in performing primary and secondary qualitative and quantitative research. With the financial support of Varian, committed students were hired as research assistants and enabled them to dedicate more time to the projects. For students, the financial support relieves a level of stress, as they are less pressured to take on part-time jobs that do not support their professional development. Over the last two years, this partnership has helped ten students develop their business talents and research capabilities. The work from this project has led to one graduate thesis and is projected to result in two undergraduate theses.

For applied research, Varian has been interested in evolving methods of radiotherapy planning to reduce dependency on a specialized labor force, which would enable more efficient implementation of treatment plans and expand services globally. Working towards this broader goal, projects have focused on the application of machine learning techniques for medical image processing. This is a rich field with wider applications, which enables the students to learn skills within the project that they can carry to new contexts in their career development. Over three years, this arm of the partnership with Varian has supported three rounds of projects, which have drawn in a total of twelve students. Similar to the business project, financial support to hire students as research assistants was also received. The work product from these projects have been a senior design thesis and tested machine learning code. 


\section{Key Outputs}

To measure the Lab's success against the multiway value proposition to deliver value to the students, faculty, and external partners, we tracked the key performance indicators as described in Table 1 (e.g., number of project students, student fellows, sponsored projects, industry mentors, faculty mentors, etc.). In addition to determining the success of the Lab through performance indicators, qualitative research was performed to ascertain the successful delivery of the value propositions. Current students, recent lab alumni, faculty mentors, and industry partners were interviewed to verify whether they received the value that was promised and expected, as well as to learn more about the impact the Lab had on them. Representatives of the University's corporate and external relations programs and the members of the advisory board for the Lab were also surveyed to learn more about the overall value the Lab brings to the University and its stakeholders.

Every year, the Lab engages close to 50 students from different disciplines across engineering, business, and the arts and sciences. Our students major in an array of subjects, from bioengineering and mechanical engineering to finance and marketing, as well as music and theater, which lends itself to the opportunity to work on interdisciplinary teams to solve a variety of problems. By building interdisciplinary teams, students are better prepared for industry engagement, which is consistent with the primary objective of the Lab. The majority of our students work on industry sponsored projects, with the engagements spanning diverse topics including automated image analysis, bio-wearable devices, diagnostics, market research, and prosthesis for emerging markets. Over the course of three years, over 100 students have participated in industry sponsored projects, with increasing numbers of students engaged year to year (17 in 2017-18, 34 in 2018-19, and 52 in 2019-20). Another way that students are engaged in the Lab is through our fellowship program or through curricular or co-curricular activities (e.g. courses, workshops, bootcamps, etc.) that allow them to focus their study of innovation and entrepreneurship to the medical field. These experiences enable students to be introduced to real world problems early in their studies and prepare themselves to serve as active members of interdisciplinary teams. Success of these co-curricular and extra-curricular activities can be observed by the increased number of student participants year over year (22 in 2017-18, 28 in 2018-19, and 43 in 2019-20). Through these activities, the Lab has successfully engaged undergraduate, master's level, and postgraduate students, which highlights our ability to involve students across all years of study and apply vertical integration. Although the program has been popular among students of all levels, first year students have not been as engaged, a weakness we hope to address in the near future through our fellowship experiences and co-curricular activities. In addition to tracking student engagement through yearly data collection, we surveyed current students and recent alumni to better understand the strengths and gaps of the Labs' value proposition to its students. As expected, most students joined the Lab to work on industry partnered projects, as well as to receive mentorship (Figure 2A). Students were also asked to complete a Likert scale questionnaire that investigated the impact of their experiences on personal and professional growth. More than half of the respondents indicated that their knowledge of healthcare, technical skills, professional skills, and career readiness has increased by a lot or a great deal (Figure 2B). 

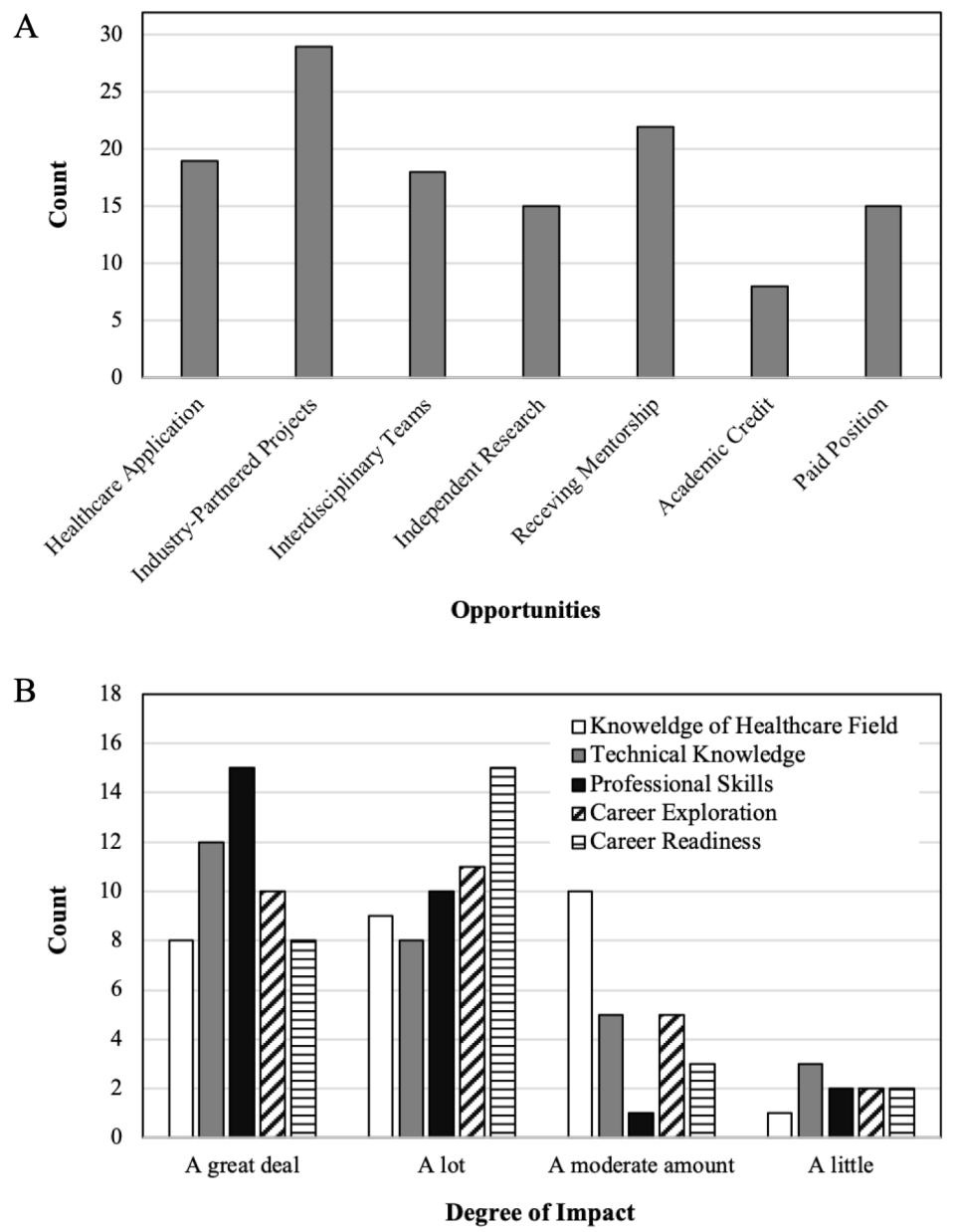

Figure 2. Quantitative results from the student survey $(n=28)$ (A) Opportunities offered by the Lab that most appealed to students, and (B) Likert scores indicating the extent to which the activities of Lab impacted students' personal and professional growth.

As a testament to the students finding value working in the Lab, all surveyed students agreed that they would or might recommend the Lab to their colleagues and almost all respondents said they would like to stay involved in the Lab in some way in the future, whether that is through projects, mentorship, fundraising, leading workshops, etc. Most telling of what the Lab means to the students was expressed in their responses to the open question: "In your own words, please describe the impact your participation in the Lab has made on you." A student said the Lab "vastly increased my knowledge of the healthcare space and allowed me to be selected for a team working on high priority business initiatives at the company I will be working at post-grad." Another student wrote the Lab provided an "opportunity to implement what I have learned as part of my course work into an actual project" and "I am a more confident individual now and learned how to behave in a professional environment." Regarding career exploration, a participant expressed, "I did not consider research as a career until I participated in a Lab project. My experience was so positive and fulfilling that I am now considering returning to school to earn a master's degree." Most notably, students felt they learned "essential skills of working on interdisciplinary team(s), meeting deadlines, developing technical skills, and much more. (They) couldn't have asked for a better opportunity to help jumpstart (their) career." Given these testimonials and yearly increase in student participation, we strongly believe we have achieved 
our goals of increasing student awareness of the healthcare space, providing opportunities for students to grow technically and professionally, and enabling them to explore career paths that will ultimately better prepare them for their futures.

In light of the students coming from diverse disciplines and training, the Lab has engaged close to fifteen faculty across multiple departments in engineering, business, and arts and sciences to mentor the student projects. The evolution of faculty involvement is driven by the growth of projects. Thus, the size and characteristics of faculty cohorts engaged with the Lab changes by year, with a cumulative increase in the range of faculty contributions (more than a two-fold increase over three years). These faculty are engaged with ten industry partnered projects and six self-conceived internal projects. With this range, faculty have the opportunity to match to areas of their interest beyond traditional formats. To gain insight into the faculty perspective, we surveyed faculty, excluding faculty mentors who are also co-authors (PA, JAS), on the relevant value proposition of the Lab. Primary types of engagement include project mentorship, general advice and mentorship, and senior design advisement. The top reasons faculty joined in Lab activities were for industry partnerships, interdisciplinary projects, and new opportunities to engage students. Unanimously, faculty (five total respondents) reported that student mentorship and training, as well as interdisciplinary collaborations, were positively impacted by the experience in the Lab. All respondents state they would recommend participation in the Lab for students and fellow faculty. This feedback shows evidence that the Lab is reaching its performance indicators, which aim to facilitate student faculty mentorship and expand collaboration across campus and with external partners.

Our external partners (twelve partners in total over the past three years) are diverse in their size and needs. The most common ways partners engage with the Lab are to provide mentoring to students, offer opportunities for internships or co-ops, or work collaboratively on projects. While the partners give value to the students, they also benefit in different forms, such as in research and development and business operations. Some partners hope to be able to use the work products from the alliance in the near term to "contribute to (their) company's capabilities." The long view of their objectives is shown in their statements, which repeated that the most important piece of partnering with the Lab was to develop a pipeline of "motivated and confident candidates" by "shap(ing) the minds of young talent." In contrast to traditional internships, partners explained that by working with our Lab's framework, they were able to reach more students, rather than a single intern, with fewer resources due to the facilitation by the faculty mentors and University infrastructure. Additionally, several industry mentors expressed that working with groups of students gave the mentors "fresh perspectives" and "opened (their) eyes in ways (they) would never have seen otherwise," resulting in project expansion into areas that were not considered previously. The flexibility of the Lab and student teams enables industry to continually learn alongside the students and faculty and achieve the greatest benefit. The major drawback in this framework is projects are ongoing during the academic year, which results in a slower pace set by the rhythms of the quarter system. Despite this natural consequence, no respondent reported that it would strongly deter future engagement and we have greater than $90 \%$ partners returning for a continued or expanded scope of the projects. And as partner organization's plans change and new partners are recruited, the Lab has a net increase in the number of projects and project mentors each year (greater than a 50\% increase in three years). 
Finally, internal representatives of the University's corporate, external relations, and fundraising units, as well as the members of the advisory board for the Lab were surveyed to provide input on the overall value offered by the Lab to the University at large. All parties agreed the Lab helped deliver on the University's mission of putting knowledge to work for others. There is also consensus that the Lab helped the University engage the private sector effectively in a myriad of ways and in a manner that was consistent with its mission and values. They were excited to see the Lab's commitment to developing a robust, multi-skilled, and diverse 21 st-century workforce pipeline. Finally, they endorsed the Lab's ability to help the University attract and retain students through providing students with increased opportunities for industry engagement, including internships and employment opportunities. Several gaps were also noted, including the need to (1) scaffold additional program management staff to oversee program and partnership growth, (2) begin to engage institutional philanthropy more proactively, (3) more fully engage graduate students, and (4) identify a donor champion to make seven-to-eight figure gift to permanently establish the program.

Consistent with the input from the advisory board and external relations personnel, we framed our donor engagement strategy around the core hypothesis that philanthropists and foundations would be highly interested in aiding initiatives that support high-value student activities and outcomes. From the outset, the activities of the Lab have received support from a steady stream of gifts and pledges, with an increasing frequency and size of donations over the last two years ( $>3$ fold-increase in the number and total dollar amount of donations). In addition to generating quantifiable increases in the number and amount of donations each year, the Lab is also attracting regular interest from the University's fundraising and donor engagement groups. The Lab has been asked to present regularly at University-wide fundraiser meetings, participated in capital campaign roadshows, the parent donor council, and individual donors across donor classes (e.g. estate donors, parents, alumni, and other major donors). Roundtable presentations have yielded individual donor meetings, proposal invitations, and multiple new commitments, often of $\$ 10,000$ or more. In addition to discrete gifts, activation of these channels is also driving deeper donor engagement and interest as demonstrated by a significant number of donors electing to give their time as executive mentors or join the Lab advisory board. We further found the interdisciplinary nature of the Lab (as a nexus point for a wide variety of disciplines) enables it to attract donors that would otherwise not support an initiative housed in the School of Engineering. As an organization founded fewer than 36 months ago, the Lab's ability to attract grants from institutional philanthropists is still nascent and will be an area for further growth in 2021 and 2022. Larger private and corporate foundations typically require a well-developed logic model, three years of impact metrics, a track record of governance, and multiple years of program delivery before considering major programmatic grants.

\section{Conclusions}

In this overview of the purpose, structure and progressive outcomes of the Lab, we have shown how a framework centered around external partnerships can facilitate an increase in student engagement, growth in an entrepreneurial mindset, and practice of design thinking for complex problems. The Lab has achieved these outputs because we have not constrained its identity to a single part of the University. Rather, we have pulled on a network of levers horizontally and vertically to support the establishment of a hub for healthcare innovation. By seeking feedback from stakeholders, we have identified how the Lab must adapt to better meet the needs of each 
and empower the students, faculty, and community to be prepared to address the demands of the healthcare challenges of tomorrow. We will sustain and scale our operations by more proactively engaging institutional and individual philanthropy as a supplement to our existing revenue streams to establish reliable and long-term funding support of the students, as well as build the infrastructure and programming needed to pursue real-world projects. We hope to share the program as a model for sustained engagement with industry and alumni that could be reproduced at other institutions of similar scale.

\section{References}

1. C.L. Dym, A.M. Agogino, O. Eris, D.D. Frey and L.J. Leifer. "Engineering Design Thinking, Teaching, and Learning," Journal of Engineering Education, vol. 94, pp. 103120, January 2005.

2. R. Razzouk and V. Shute. "What Is Design Thinking and Why Is It Important?" Review of Educational Research, vol. 82, no. 3, pp. 330-348, September 2012.

3. G. Theyel, A.B. Morales, E. Bouzos and P. Asuri. "Enhancing Senior Engineering Student Projects by Incorporating Needs Assessment, Manufacturing Engineering, and Pilot Testing," International Journal of Engineering Education, vol. 37, no. 1, pp: 195203, January 2021.

4. IDEO.org. The Field Guide to Human-Centered Design, 1st Ed. 2015. [eBook] Available: https://www.designkit.org/resources/1

5. D. Rae and D.E. Melton. "Developing an entrepreneurial mindset in US engineering education: an international view of the KEEN project," The Journal of Engineering Entrepreneurship, vol. 7, pp: 1-16, 2016.

6. R. Nagel, K. Holland, K. Gipson, J. Henriques and K. Paterson. "Creating an Ecosystem that Fosters Innovation and Entrepreneurial Mindset at an Undergraduate Institution through Pathways to Innovation," Advances in Engineering Education, Spring 2020.

7. W. Clark and M. Besterfield-Sacre, "Full Court Press as a Come-From-Behind Strategy to Win the Innovation and Entrepreneurship Game: A Case Study at the University of Pittsburgh," Advances in Engineering Education, Spring 2020. 